\title{
Interface formation and thermal stability of advanced metal gate and ultrathin gate dielectric layers
}

\author{
B. Claflin a) and G. Lucovsky \\ Department of Physics, North Carolina State University, Raleigh, North Carolina 27695-8202
}

(Received 21 January 1998; accepted 28 May 1998)

\begin{abstract}
The compatibility of metallic titanium nitride $\left(\mathrm{TiN}_{x}\right)$ films for advanced gate electrodes and remote plasma enhanced chemical vapor deposited silicon oxide $\left(\mathrm{SiO}_{2}\right)$ or silicon oxide/silicon nitride $\left(\mathrm{Si}_{3} \mathrm{~N}_{4}\right)$ advanced gate dielectric layers is investigated by interrupted growth and on-line rapid thermal annealing using on-line Auger electron spectroscopy. Growth of $\mathrm{TiN}_{x}$ on $\mathrm{SiO}_{2}$ and $\mathrm{Si}_{3} \mathrm{~N}_{4}$ occurs uniformly without a titanium seed layer. $\mathrm{TiN}_{x} / \mathrm{SiO}_{2}$ and $\mathrm{TiN}_{x} / \mathrm{Si}_{3} \mathrm{~N}_{4}$ interfaces are chemically stable against reaction for rapid thermal annealing treatments below $850{ }^{\circ} \mathrm{C}$. Metaloxide-semiconductor capacitors using $\mathrm{TiN}_{x}$ gate contacts and $\mathrm{SiO}_{2}$ or $\mathrm{SiO}_{2} / \mathrm{Si}_{3} \mathrm{~N}_{4}$ gate dielectrics exhibit excellent $C-V$ characteristics. The measured $\mathrm{TiN}_{x} / \mathrm{SiO}_{2}$ barrier height in these devices is $\Phi_{b}=3.7 \pm 0.1 \mathrm{eV}$. The observed difference in fixed charge for $\mathrm{SiO}_{2}$ and $\mathrm{SiO}_{2} / \mathrm{Si}_{3} \mathrm{~N}_{4}$ dielectrics is briefly discussed in terms of a new interface dipole model. (c) 1998 American Vacuum Society. [S0734-211X(98)11704-3]
\end{abstract}

\section{INTRODUCTION}

The continuing effort to reduce metal-oxidesemiconductor (MOS) device dimensions has led to considerable interest in silicon oxide ${ }^{1}\left(\mathrm{SiO}_{2}\right)$ and silicon oxide/ silicon nitride ${ }^{2,3}\left(\mathrm{Si}_{3} \mathrm{~N}_{4}\right)$ layered films with an equivalent oxide thickness $t_{\text {ox-eq }}<3 \mathrm{~nm}$ for advanced gate dielectrics. Similarly, to maintain proper device scaling and to avoid the effects of gate electrode depletion, attention is being focused on advanced gate materials such as metallic titanium nitride ${ }^{4-8}\left(\mathrm{TiN}_{x}\right)$ as a possible replacement for heavily doped polycrystalline silicon. However, before such materials can be incorporated into device production they must be shown to be compatible with the other materials and with subsequent process conditions required for fabrication. Of particular concern is the possibility of chemical reaction at the interface between these advanced dielectric and gate materials at elevated temperatures. ${ }^{9,10}$ For example, the gate metal/ dielectric interface must be able to withstand rapid thermal annealing (RTA) temperatures of at least $800-1000{ }^{\circ} \mathrm{C}$ which are required to activate dopants in source and drain structures.

In this article, the interface formation between reactively sputtered $\mathrm{TiN}_{x}$ metallic films and $\mathrm{SiO}_{2}$ or $\mathrm{SiO}_{2} / \mathrm{Si}_{3} \mathrm{~N}_{4}$ dielectric layers prepared by low-temperature remote plasma enhanced chemical vapor deposition (RPECVD) is investigated as well as the chemical stability of these interfaces following on-line RTA treatments up to $850{ }^{\circ} \mathrm{C}$. The evolution of the $\mathrm{TiN}_{x} / \mathrm{SiO}_{2}$ and $\mathrm{TiN}_{x} / \mathrm{Si}_{3} \mathrm{~N}_{4}$ interfaces is investigated from their initial formation at the monolayer level to the buried interface by interrupted film growth using on-line Auger electron spectroscopy (AES). The stability of $\mathrm{TiN}_{x} / \mathrm{SiO}_{2}$ and $\mathrm{TiN}_{x} / \mathrm{Si}_{3} \mathrm{~N}_{4}$ interfaces against reaction during RTA treatments at temperatures below $850{ }^{\circ} \mathrm{C}$ is also established by on-line AES. Finally, capacitance-voltage $(C-V)$ characteristics of MOS capacitors employing $\mathrm{TiN}_{x}$ gate electrodes

${ }^{a}$ Electronic mail: claflin@ncsu.edu with ultrathin single layer $\mathrm{SiO}_{2}$ and dual layer $\mathrm{SiO}_{2} / \mathrm{Si}_{3} \mathrm{~N}_{4}$ gate dielectrics are presented. These $C-V$ results are compared with similar MOS devices made using $\mathrm{Al}$ gate contacts.

\section{EXPERIMENT}

Interrupted growth and chemical stability experiments were conducted on 3 in. $p$-type $\mathrm{Si}(100)$ wafers on which either a single layer $\mathrm{SiO}_{2}$ dielectric or a dual layer $\mathrm{SiO}_{2} / \mathrm{Si}_{3} \mathrm{~N}_{4}$ dielectric stack was deposited. In both cases, the $\mathrm{SiO}_{2}$ layer was $5 \mathrm{~nm}$ thick and was prepared by a two-step plasma assisted oxidation/RPECVD process ${ }^{1}$ which is described in detail elsewhere. The $\mathrm{Si}_{3} \mathrm{~N}_{4}$ layer was $3 \mathrm{~nm}$ thick and was deposited by RPECVD with $\mathrm{NH}_{3}$ and $\mathrm{SiH}_{4}$ source gases injected downstream ${ }^{2,11,12}$ at a ratio of 10:1. Prior to $\mathrm{TiN}_{x}$ deposition, the $\mathrm{SiO}_{2}$ and $\mathrm{SiO}_{2} / \mathrm{Si}_{3} \mathrm{~N}_{4}$ dielectric layers were subjected to a $30 \mathrm{~s}$ RTA treatment at $900{ }^{\circ} \mathrm{C}$ to improve their electrical properties by reducing bond defects. ${ }^{13,14}$ This bonding rearrangement was verified by Fourier transform infrared (FTIR) spectroscopy.

Metallic $\mathrm{TiN}_{x}$ films were deposited at room temperature by reactive dc magnetron sputtering of a $99.9 \% \mathrm{Ti}$ target at $50 \mathrm{~W}$ with a 5:1 mixture of $99.999 \% \mathrm{Ar}$ and $99.999 \% \mathrm{~N}_{2}$ at a chamber pressure of $6 \mathrm{mTorr}$. Several ultrathin $\mathrm{TiN}_{x}$ layers were deposited sequentially and AES spectra collected until the $\mathrm{Si}_{L V V}$ Auger peak could no longer be observed, indicating that the interface had been buried. Thicker $\operatorname{TiN}_{x}$ layers (each about $0.5-1.0 \mathrm{~nm}$ ) were then added until bulk characteristics were observed. To study the chemical stability of the metal/dielectric interfaces, a $0.6-1.0 \mathrm{~nm}$ thick $\mathrm{TiN}_{x}$ layer was deposited on $\mathrm{SiO}_{2}$ or $\mathrm{SiO}_{2} / \mathrm{Si}_{3} \mathrm{~N}_{4}$ and annealed in vacuum for $180 \mathrm{~s}$ in $100{ }^{\circ} \mathrm{C}$ steps from 350 to $850{ }^{\circ} \mathrm{C}$. Following each on-line RTA treatment, AES spectra were collected.

MOS capacitors were prepared on $n$-type $\mathrm{Si}(100)$ wafers with ultrathin $\mathrm{SiO}_{2}$ or $\mathrm{SiO}_{2} / \mathrm{Si}_{3} \mathrm{~N}_{4}$ dielectrics and $\mathrm{TiN}_{x}$ or $\mathrm{Al}$ gate electrodes. The wafers were cleaned, a thermal field 


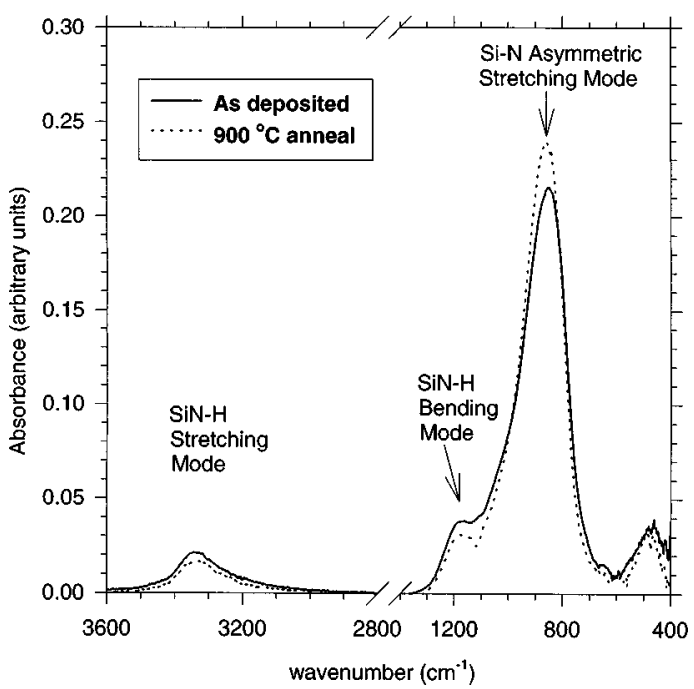

FIG. 1. FTIR spectra of RPECVD $\mathrm{Si}_{3} \mathrm{~N}_{4}$ dielectric as deposited and following a $30 \mathrm{~s} 900{ }^{\circ} \mathrm{C}$ RTA treatment. The decrease of $\mathrm{SiN}-\mathrm{H}$ stretch and bending modes while the $\mathrm{Si}-\mathrm{N}$ asymmetric stretch increases after annealing indicates conversion of $\mathrm{SiN}-\mathrm{H}$ dangling bonds to $\mathrm{Si}-\mathrm{N}$ network bonds.

oxide was grown and patterned, and the active area wet chemically etched. The wafers were cleaned again prior to RPECVD deposition of a $3.5 \mathrm{~nm} \mathrm{SiO}_{2}$ gate dielectric or a 2.0 $\mathrm{nm} \mathrm{SiO} / 2.0 \mathrm{~nm} \mathrm{Si}_{3} \mathrm{~N}_{4}$ dielectric bilayer. The wafers were patterned for liftoff and a $50 \mathrm{~nm} \mathrm{TiN}_{x}$ or $100 \mathrm{~nm} \mathrm{Al}$ gate electrode deposited by sputtering. A $100 \mathrm{~nm}$ thick Al layer was sputtered on top of the $\mathrm{TiN}_{x}$ gate to facilitate external contact. Liftoff was performed, Al back contacts evaporated, and the samples were annealed at $300{ }^{\circ} \mathrm{C}$ in $\mathrm{H}_{2}$ for $1800 \mathrm{~s}$. Standard high frequency $(100 \mathrm{kHz}) C-V$ measurements were conducted to determine the device characteristics.

\section{RESULTS AND DISCUSSION}

To evaluate the integration of $\mathrm{TiN}_{x}$ and RPECVD dielectrics with existing Si technology and process flows it is critical to use optimal preparation conditions for these new materials. It has been shown ${ }^{13}$ previously that a $15 \mathrm{~s}, 900{ }^{\circ} \mathrm{C}$ RTA treatment improves the dielectric quality of RPECVD $\mathrm{SiO}_{2}$ films by reducing the amount of suboxide $\left(\mathrm{SiO}_{x}\right.$ with $x<2$ ) at the $\mathrm{Si} / \mathrm{SiO}_{2}$ interface and hence the number of electrically active dangling bond defects. A similar improvement in the dielectric reliability of RPECVD $\mathrm{Si}_{3} \mathrm{~N}_{4}$ films occurs ${ }^{14}$ by annealing at $900{ }^{\circ} \mathrm{C}$ for $30 \mathrm{~s}$ and can be monitored with FTIR as seen in Fig. 1. The spectrum displays three main features: a $\mathrm{Si}-\mathrm{N}$ asymmetric stretching mode at approximately $850 \mathrm{~cm}^{-1}$, a SiN-H bending mode at $1200 \mathrm{~cm}^{-1}$, and a $\mathrm{SiN}-\mathrm{H}$ stretching mode near $330 \mathrm{~cm}^{-1}$. Figure 1 shows a decrease in the intensity of $\mathrm{SiN}-\mathrm{H}$ bending and stretching modes while the $\mathrm{Si}-\mathrm{N}$ asymmetric stretch increases from as-deposited levels following a $900{ }^{\circ} \mathrm{C}$ RTA treatment. These changes in the IR spectra have recently been explained ${ }^{14}$ as resulting from a conversion of correlated $\mathrm{Si}-\mathrm{H}$ and $\mathrm{SiN}-\mathrm{H}$ dangling bonds into $\mathrm{Si}-\mathrm{N}$ network bonds.

$\mathrm{SiO}_{2}$ and $\mathrm{SiO}_{2} / \mathrm{Si}_{3} \mathrm{~N}_{4}$ dielectric films optimized in this fashion were used to study the interface formation, growth,

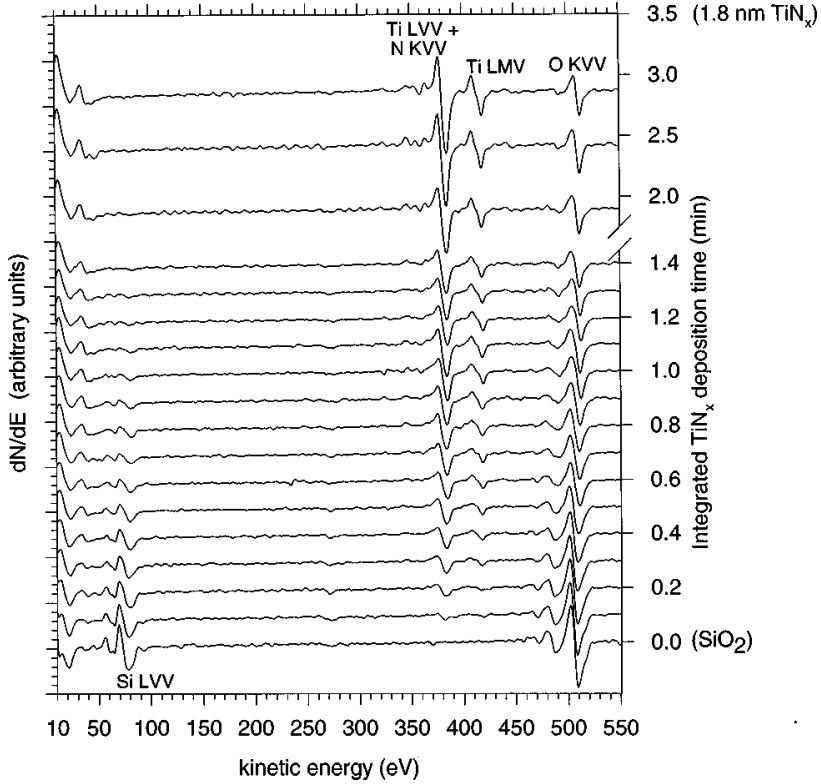

FIG. 2. Interrupted growth of $\mathrm{TiN}_{x}$ on RPECVD $\mathrm{SiO}_{2}$ measured by AES. $\mathrm{Si}_{L V V}$ and $\mathrm{O}_{K V V}$ peaks decrease while $\mathrm{Ti}_{L V V}+\mathrm{N}_{K V V}$ and $\mathrm{Ti}_{L M V}$ peaks increase with additional $\mathrm{TiN}_{x}$ deposition. The asymmetry of $\mathrm{Ti}_{L V V}+\mathrm{N}_{K V V}$ and $\mathrm{Ti}_{L M V}$ intensities indicates no Ti seed layer is required.

and chemical stability of $\operatorname{TiN}_{x}$. Derivative AES spectra demonstrating the growth of $\mathrm{TiN}_{x}$ on RPECVD $\mathrm{SiO}_{2}$ are provided in Fig. 2 with the relevant Auger transitions indicated. The bottom curve shows the spectrum for the bare $\mathrm{SiO}_{2}$ dielectric layer. The vertical offset of subsequent curves corresponds to the integrated $\mathrm{TiN}_{x}$ sputtering time elapsed, indicated by the right-hand axis. Film thickness was estimated from the bulk deposition rate of $1.0 \mathrm{~nm} / \mathrm{min}$ which was determined by cross-sectional scanning electron microscopy on thick samples.

A quantative difficulty which arises in the $\mathrm{TiN}_{x}$ system is that the $\mathrm{Ti}_{L V V}$ and $\mathrm{N}_{K V V}$ AES peaks overlap ${ }^{15-17}$ at $385 \mathrm{eV}$; however the $\mathrm{Ti}_{L M V}$ feature at $420 \mathrm{eV}$ does not suffer from this deficiency. For $\mathrm{TiN}_{x}$, the $\mathrm{Ti}_{L V V}+\mathrm{N}_{K V V}$ and $\mathrm{Ti}_{L M V}$ features exhibit a peak to peak intensity ratio that is about $2: 1$. In contrast, for pure $\mathrm{Ti}$ the intensity of these two peaks would be nearly equal. ${ }^{8}$ In Fig. 2 the $\mathrm{Ti}_{L V V}+\mathrm{N}_{K V V}$ feature is seen to form and grow on $\mathrm{SiO}_{2}$ as additional layers of $\mathrm{TiN}_{x}$ are added and the intensity of this peak is always about twice that of $\mathrm{Ti}_{L M V}$. This asymmetry in these peak intensities, which occurs even for submonolayer coverage, indicates that $\mathrm{TiN}_{x}$ grows directly on $\mathrm{SiO}_{2}$ without the need for an intermediate $\mathrm{Ti}$ seed layer. The $\mathrm{Si}_{L V V}$ peak intensity at $76 \mathrm{eV}$ decreases as successive $\mathrm{TiN}_{x}$ layers are deposited and disappears entirely for a metal thickness greater than about 0.8 nm. The $\mathrm{O}_{K V V}$ peak near $510 \mathrm{eV}$ also initially decreases; however a small amount of parasitic oxygen is always observed even after the $\mathrm{TiN}_{x} / \mathrm{SiO}_{2}$ interface is completely buried and bulk $\mathrm{TiN}_{x}$ features are observed.

Figure 3 shows similar derivative AES spectra for interrupted $\mathrm{TiN}_{x}$ growth on $\mathrm{Si}_{3} \mathrm{~N}_{4}$. Because the dielectric contains nitrogen, the initial development of the $\mathrm{Ti}_{L V V}+\mathrm{N}_{K V V}$ feature is impossible to observe. However, the $\mathrm{Ti}_{L M V}$ peak evolution 


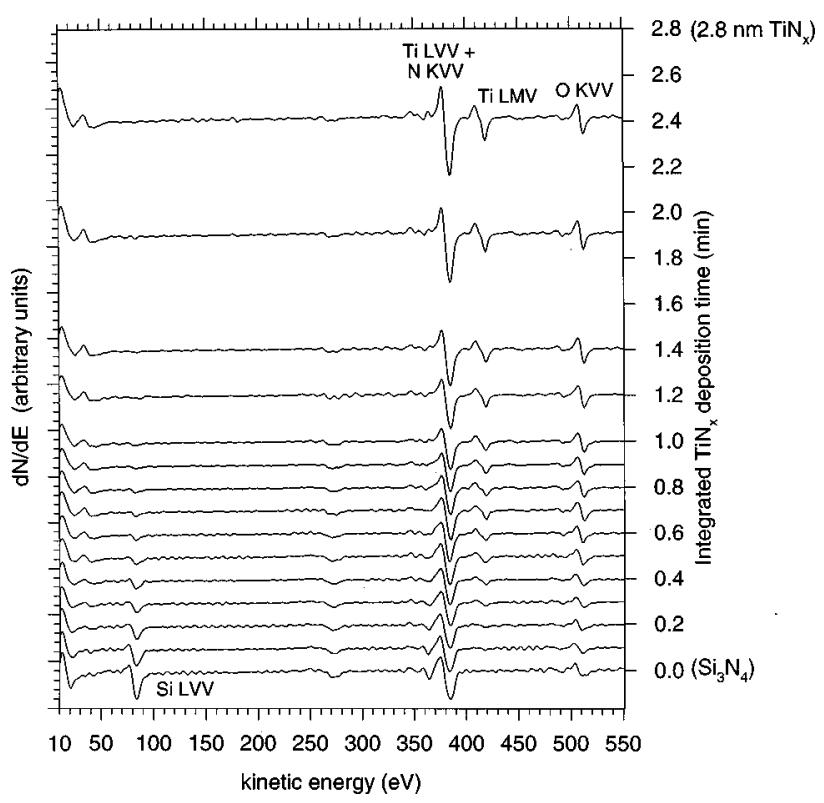

FIG. 3. Interrupted growth of $\mathrm{TiN}_{x}$ on RPECVD $\mathrm{Si}_{3} \mathrm{~N}_{4}$ measured by AES. The $\mathrm{Si}_{L V V}$ peak decreases while the $\mathrm{Ti}_{L V V}+\mathrm{N}_{K V V}$ and $\mathrm{Ti}_{L M V}$ peaks increase with additional $\mathrm{TiN}_{x}$ deposition. The similarity in growth of the $\mathrm{Ti}_{L M V}$ peak to Fig. 2 suggests that no seed layer is required.

on $\mathrm{Si}_{3} \mathrm{~N}_{4}$ is similar to the behavior observed in Fig. 2 on $\mathrm{SiO}_{2}$ and suggests that $\mathrm{TiN}_{x}$ grows directly on $\mathrm{Si}_{3} \mathrm{~N}_{4}$ without a buffer layer. The $\mathrm{Si}_{L V V}$ peak intensity in Fig. 3 is diminished by successive $\operatorname{TiN}_{x}$ layers and disappears above about 0.8 $\mathrm{nm}$ as expected.

The decrease of the $\mathrm{Si}_{L V V}$ peak intensity normalized to its value in the bare dielectric is plotted on a $\log$ scale as a function of $\mathrm{TiN}_{x}$ deposition time in Fig. 4 for both the $\mathrm{SiO}_{2}$ and the $\mathrm{SiO}_{2} / \mathrm{Si}_{3} \mathrm{~N}_{4}$ substrates. In both cases the intensity decreases exponentially with $\operatorname{TiN}_{x}$ thickness although the slopes differ by about a factor of 2 . This exponential de-

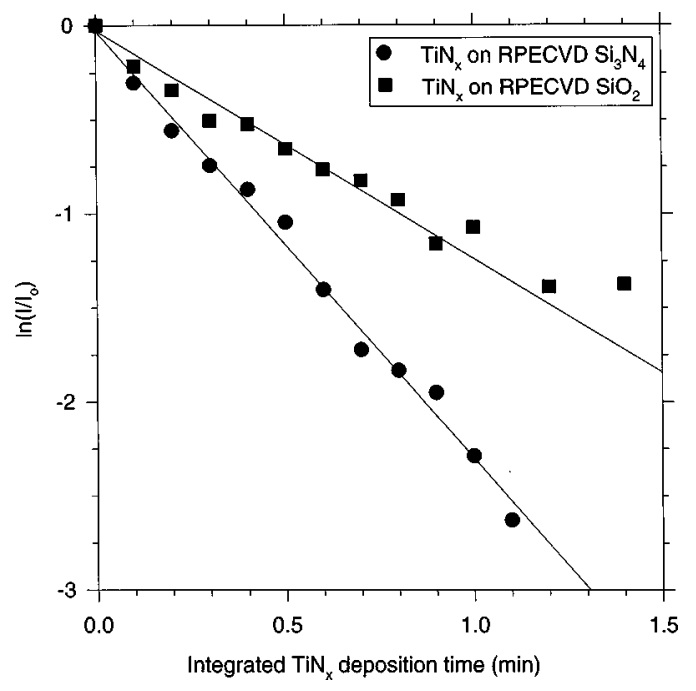

FIG. 4. Decrease of normalized $\mathrm{Si}_{L V V}$ AES peak intensity with increasing $\mathrm{TiN}_{x}$ deposition on $\mathrm{SiO}_{2}$ and $\mathrm{Si}_{3} \mathrm{~N}_{4}$ dielectric layers. The exponential decay indicates uniform $\operatorname{TiN}_{x}$ layer growth on both dielectrics.

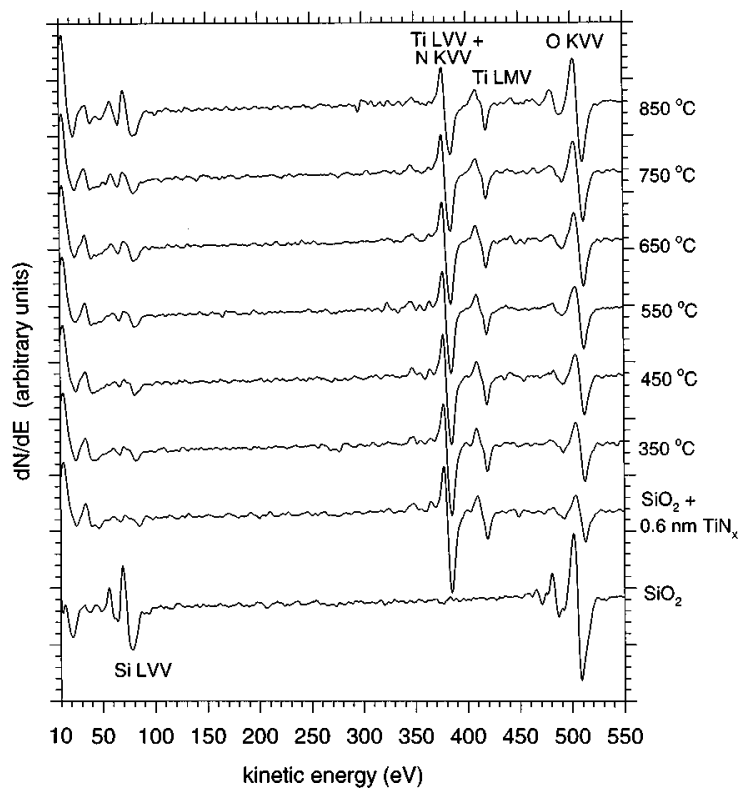

FIG. 5. Chemical stability of $\mathrm{TiN}_{x} / \mathrm{SiO}_{2}$ interface following the RTA treatments indicated. The dramatic increase of the $\mathrm{Si}_{L V V}$ AES peak at $850{ }^{\circ} \mathrm{C}$ indicates that a reaction has occurred.

crease of the $\mathrm{Si}_{L V V}$ peak intensity with $\mathrm{TiN}_{x}$ thickness indicates uniform layer growth on both $\mathrm{SiO}_{2}$ and $\mathrm{Si}_{3} \mathrm{~N}_{4}$. The difference in the slopes of these curves corresponds to different deposition rates due to target aging. Detailed kinetics of the interface formation and morphology of the $\mathrm{TiN}_{x}$ layer in each case require further investigation.

Derivative AES spectra for $\mathrm{TiN}_{x} / \mathrm{SiO}_{2}$ and $\mathrm{TiN}_{x} / \mathrm{Si}_{3} \mathrm{~N}_{4}$ interfaces subjected to on-line RTA treatments up to $850{ }^{\circ} \mathrm{C}$ are shown in Figs. 5 and 6, respectively. In both cases, a

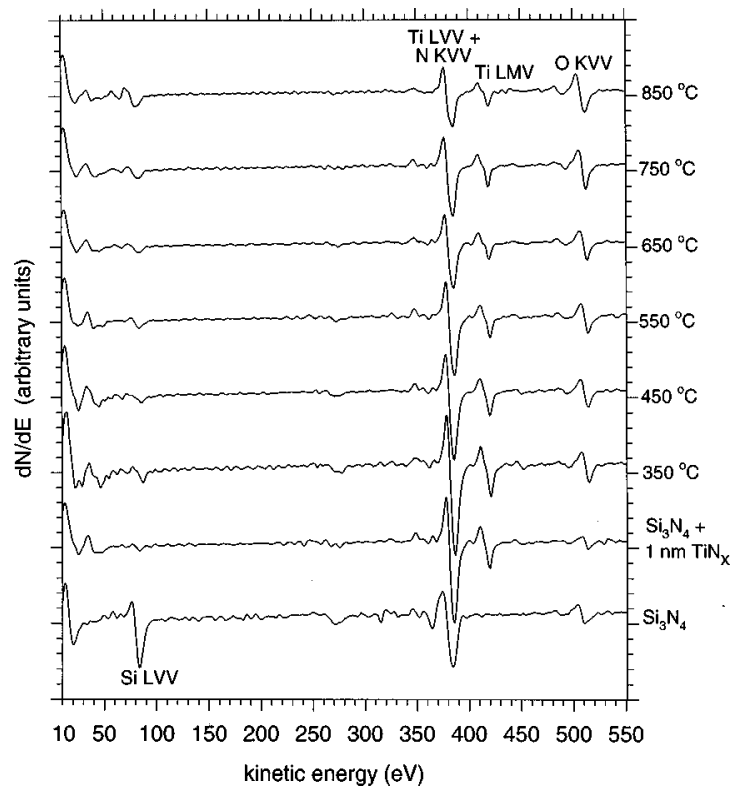

FIG. 6. Chemical stability of $\mathrm{TiN}_{x} / \mathrm{Si}_{3} \mathrm{~N}_{4}$ interface following the RTA treatments indicated. A slight increase of the $\mathrm{Si}_{L V V} \mathrm{AES}$ peak at $850^{\circ} \mathrm{C}$ indicates that the interface is chemically stable. 


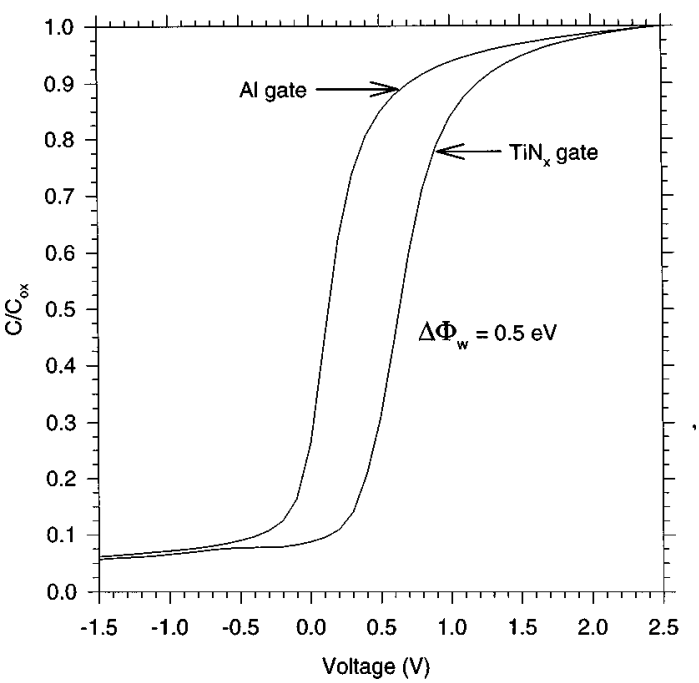

FIG. 7. High frequency $C-V$ data for MOS capacitors using $\mathrm{TiN}_{x}$ or $\mathrm{Al}$ gates and a $3.5 \mathrm{~nm} \mathrm{RPECVD} \mathrm{SiO}_{2}$ gate dielectric. The flatband voltage shift corresponds to the work function difference between $\mathrm{TiN}_{x}$ and $\mathrm{Al}$.

minimal thickness of $\operatorname{TiN}_{x}$ was deposited to bury the interface, reducing the $\mathrm{Si}_{L V V}$ peak intensity to nearly zero. Only minor changes in the AES spectra for both $\mathrm{TiN}_{x} / \mathrm{SiO}_{2}$ and $\mathrm{TiN}_{x} / \mathrm{Si}_{3} \mathrm{~N}_{4}$ interfaces are observed below $850{ }^{\circ} \mathrm{C}$ and are most likely the result of slight variations in thickness of the $\mathrm{TiN}_{x}$ overlayer. Following the $850^{\circ} \mathrm{C}$ anneal, however, the $\mathrm{Si}_{L V V}$ peak intensity increases substantially for the $\mathrm{TiN}_{x} / \mathrm{SiO}_{2}$ interface and modestly for $\mathrm{TiN}_{x} / \mathrm{Si}_{3} \mathrm{~N}_{4}$. The fact that these changes in the AES spectra occur at the same temperature for both dielectrics suggests that decomposition of $\mathrm{TiN}_{x}$ begins at $850{ }^{\circ} \mathrm{C}$. The dramatic change in the $\mathrm{TiN}_{x} / \mathrm{SiO}_{2}$ interface compared to that of $\mathrm{TiN}_{x} / \mathrm{Si}_{3} \mathrm{~N}_{4}$ indicates that the metal chemically reacts with the underlying $\mathrm{SiO}_{2}$ layer but does not interact with $\mathrm{Si}_{3} \mathrm{~N}_{4}$. The details of this reaction and the chemical structure that results, including the possible formation of a titanium silicide layer, still need to be elucidated.

High frequency $C-V$ characteristics for MOS capacitors using $\mathrm{TiN}_{x}$ and $\mathrm{Al}$ gates on ultrathin $\mathrm{RPECVD} \mathrm{SiO}_{2}$ dielectrics are shown in Fig. 7. The flatband voltage for the $\mathrm{TiN}_{x}$ gate is shifted by $\Delta \Phi=0.5 \pm 0.1 \mathrm{eV}$ above Al. A similar shift $\Delta \Phi=0.4 \pm 0.1 \mathrm{eV}$ is observed in Fig. 8 for capacitors with $\mathrm{TiN}_{x}$ and $\mathrm{Al}$ gates on a $\mathrm{SiO}_{2} / \mathrm{Si}_{3} \mathrm{~N}_{4}$ bilayer. In each case, the flatband voltage shift results from the work function difference of the two metals. Using the known ${ }^{18}$ barrier height of $3.2 \mathrm{eV}$ for $\mathrm{Al}$ on $\mathrm{SiO}_{2}$, the observed flatband voltage shift gives a barrier height of $\Phi_{b}=3.7 \pm 0.1 \mathrm{eV}$ for $\mathrm{TiN}_{x} / \mathrm{SiO}_{2}$, in agreement with previous studies. ${ }^{8}$ Comparing the two devices with $\operatorname{TiN}_{x}$ gates, there is an additional flatband voltage shift $\Delta \Phi=0.3 \mathrm{eV}$ between the capacitors using $\mathrm{SiO}_{2}$ and $\mathrm{SiO}_{2} / \mathrm{Si}_{3} \mathrm{~N}_{4}$ dielectrics as seen in Fig. 9. This flatband voltage shift is not due to a work function difference between the contacts since the same gate metal and substrate were used in each device. Instead, this difference in flatband voltage must result from fixed positive charge in the dielectric. However, since the wafers were processed in parallel and subjected to

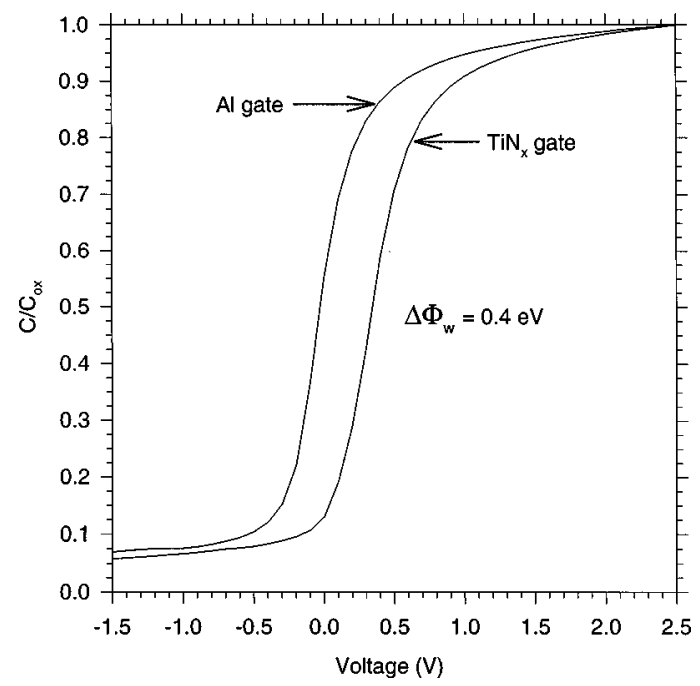

FIG. 8. High frequency $C-V$ data for MOS capacitors using $\mathrm{TiN}_{x}$ or $\mathrm{Al}$ gates and a $2 \mathrm{~nm}$ RPECVD $\mathrm{SiO}_{2} / 2 \mathrm{~nm} \mathrm{RPECVD} \mathrm{Si}_{3} \mathrm{~N}_{4}$ gate dielectric stack. The flatband voltage shift corresponds to the work function difference between $\operatorname{TiN}_{x}$ and Al.

the same treatments at each step except for deposition of the dielectric layer, it is assumed that this fixed positive charge is intrinsic to the dielectric and does not result from device processing. The most likely source of this fixed charge is an interface dipole layer in the dielectric. Recent calculations ${ }^{19}$ suggest that dipole layers between $\mathrm{Si} / \mathrm{SiO}_{x}$ and $\mathrm{Si} / \mathrm{Si}_{3} \mathrm{~N}_{4}$ interfaces may account for the observed flatband voltage shift.

\section{CONCLUSIONS}

As MOS device dimensions are reduced, the impact of interface physics on their operation and performance increases dramatically. Understanding, controlling, and optimizing interface properties will be critical to continued de-

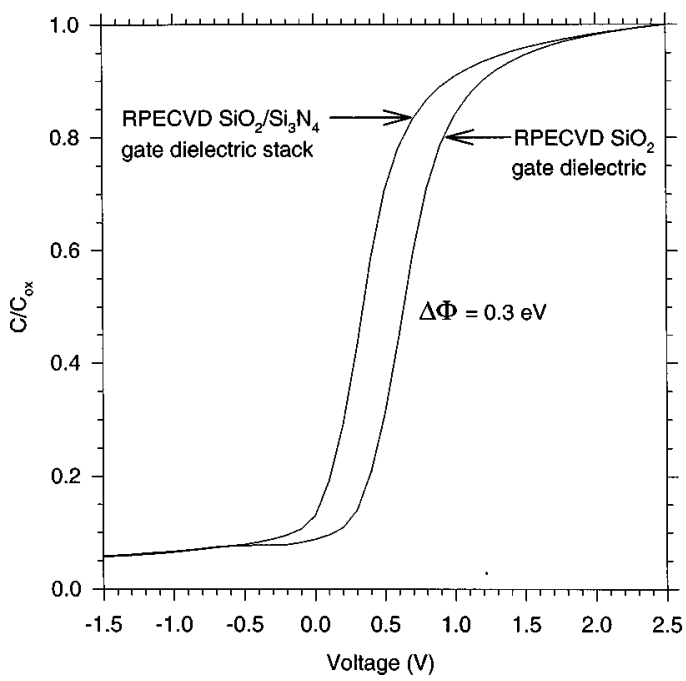

FIG. 9. Comparison of high frequency $C-V$ curves for MOS capacitors using $\mathrm{TiN}_{x}$ gates and ultrathin $\mathrm{SiO}_{2}$ or $\mathrm{SiO}_{2} / \mathrm{Si}_{3} \mathrm{~N}_{4}$ gate dielectrics from Figs. 7 and 8 . The flatband voltage shift due to fixed charge may result from interface dipoles. 
vice scaling. In particular, issues relating to the integration of novel gate dielectrics and gate metals with existing $\mathrm{Si}$ technology and process flows must be investigated and verified.

Metallic $\mathrm{TiN}_{x}$ gates are compatible with advanced RPECVD $\mathrm{SiO}_{2}$ dielectric layers and $\mathrm{SiO}_{2} / \mathrm{Si}_{3} \mathrm{~N}_{4}$ dielectric stacks. $\mathrm{TiN}_{x}$ grows uniformly on these dielectrics without an intermediate seed layer. $\mathrm{TiN}_{x} / \mathrm{SiO}_{2}$ and $\mathrm{TiN}_{x} / \mathrm{Si}_{3} \mathrm{~N}_{4}$ interfaces are stable against chemical reaction for RTA treatments below $850{ }^{\circ} \mathrm{C}$. At $850{ }^{\circ} \mathrm{C}$, the metal reacts with $\mathrm{SiO}_{2}$ possibly due to decomposition of $\operatorname{TiN}_{x}$, but is more stable on $\mathrm{Si}_{3} \mathrm{~N}_{4}$.

MOS capacitors have been fabricated which integrate $\mathrm{TiN}_{x}$ gate electrodes with RPECVD $\mathrm{SiO}_{2}$ or $\mathrm{SiO}_{2} / \mathrm{Si}_{3} \mathrm{~N}_{4}$ gate dielectrics and exhibit good $C-V$ characteristics. From the flatband voltage shift of the $C-V$ curves for $\mathrm{TiN}_{x}$ gates relative to $\mathrm{Al}$, a barrier height of $\Phi_{b}=3.7 \pm 0.1 \mathrm{eV}$ for $\operatorname{TiN}_{x}$ on $\mathrm{SiO}_{2}$ is determined. In addition, a flatband voltage shift $\Delta \Phi$ $=0.3 \mathrm{eV}$ is observed between $\mathrm{TiN}_{x}$ gates on $\mathrm{SiO}_{2}$ and $\mathrm{SiO}_{2} / \mathrm{Si}_{3} \mathrm{~N}_{4}$ gate dielectrics. This difference may result from a change in the charge dipole layer in the dielectric.

\section{ACKNOWLEDGMENTS}

The authors would like to thank D. M. Wolfe for assistance with RPECVD $\mathrm{SiO}_{2}$ and $\mathrm{Si}_{3} \mathrm{~N}_{4}$ deposition and M. Binger for assistance with data analysis. This work was supported by the ONR, NSF ERC, and SRC.

${ }^{1}$ T. Yatsuda, Y. Ma, S. Habermehl, and G. Lucovsky, Appl. Phys. Lett. 60, 434 (1992).
${ }^{2}$ Y. Ma, T. Yatsuda, and G. Lucovsky, J. Vac. Sci. Technol. B 11, 1533 (1993).

${ }^{3}$ Y. Ma, T. Yatsuda, and G. Lucovsky, J. Vac. Sci. Technol. A 11, 952 (1993).

${ }^{4}$ M. Wittmer, J. R. Noser, and H. Melchior, J. Appl. Phys. 54, 1423 (1983).

${ }^{5}$ D. H. Lee, K. H. Yeom, M. H. Cho, N. S. Kang, and T. E. Shim, 1996 Symposium on VLSI Technology, p. 208.

${ }^{6}$ D. H. Lee, S. H. Joo, G. H. Lee, J. Moon, T. E. Shim, and J. G. Lee, 1995 Symposium on VLSI Technology, p. 119.

${ }^{7}$ K. T. Kim, L. G. Kang, T. S. Park, Y. S. Shin, J. K. Park, C. J. Lee, C. G. Hwang, D. Chin, and Y. E. Park, 1990 Symposium on VLSI Technology, p. 115.

${ }^{8}$ B. Claflin, M. Binger, and G. Lucovsky, J. Vac. Sci. Technol. A 16, 1757 (1998).

${ }^{9}$ S. Q. Wang and J. W. Mayer, J. Appl. Phys. 64, 4711 (1988).

${ }^{10}$ R. Pretorius, J. M. Harris, and M.-A. Nicolet, Solid-State Electron. 21, 667 (1978).

${ }^{11}$ Y. Ma, Ph.D. thesis, North Carolina State University, 1993.

${ }^{12}$ M. J. Williams, Ph.D. thesis, North Carolina State University, 1994.

${ }^{13}$ G. Lucovsky, A. Banerjee, B. Hinds, B. Claflin, K. Koh, and H. Yang, J. Vac. Sci. Technol. B 15, 1074 (1997), and references therein.

${ }^{14}$ Z. Lu, P. Santos-Filho, G. Stevens, M. J. Williams, and G. Lucovsky, J. Vac. Sci. Technol. A 13, 607 (1995).

${ }^{15}$ W. Pamler, Surf. Interface Anal. 13, 55 (1988).

${ }^{16}$ A. J. Perry, C. Strandberg, W. D. Sproul, S. Hoffman, C. Ernsberger, J. Nickerson, and L. Chollet, Thin Solid Films 153, 169 (1987).

${ }^{17}$ B. J. Burrow, A. E. Morgan, and R. C. Ellwanger, J. Vac. Sci. Technol. A 4, 2463 (1986)

${ }^{18}$ B. E. Deal, E. H. Snow, and C. A. Mead, J. Phys. Chem. Solids 27, 1873 (1966).

${ }^{19}$ H. Z. Massoud, G. Lucovsky, and H. Yang, J. Vac. Sci. Technol. B, these proceedings. 